\title{
A ATUAÇÃo do PEDAGOGo NO MST: REVELAÇÓES DE UM ESTUDO EXPLORATÓRIO
}

\author{
Georgia Sobreira dos Santos Cêa* \\ Camila Ferreira da Silva** \\ Samara Santos Marques de Gusmáo*** \\ Thayanne Araújo Silva****
}

Em 2006, os cursos de graduação em Pedagogia foram definidos como uma licenciatura que deve prever a formação do pedagogo para atuação em espaços escolares e náo escolares, incluindo os movimentos sociais. Este artigo objetiva apresentar uma experiência curricular, denominada "Projetos Integradores", que tomou como objeto a atuação desse profissional no Movimento dos Trabalhadores Rurais Sem-Terra (MST) e envolveu docentes e discentes do $2^{\circ}$ período do curso de Pedagogia da Universidade Federal de Alagoas (UFAL). Neste artigo, reflete-se sobre a importância do tratamento das relaçóes entre movimentos sociais e educação na formação de pedagogos, apresenta-se o percurso metodológico do estudo realizado e expóem-se significativas aprendizagens por ele proporcionadas, com destaque para a compreensão das relaçôes entre a luta pela terra e a educação, enfatizando as ações realizadas por um pedagogo no MST.

Palavras-chave: Atuação do pedagogo. Educação e movimentos sociais. Educação e MST.
*Doutora em Educação: História, Política e Sociedade PUC-SP; Professora Adjunta do Centro de Educação - UFAL. Maceió - AL [Brasil] gecea@uol.com.br

** Graduanda do Curso de Pedagogia - UFAL. Maceió - AL - Brasil miluxafs@gmail.com

${ }^{* * *}$ Graduanda do Curso de Pedagogia - UFAL. Maceió - AL - Brasil sagusmao@gmail.com

****Graduanda do Curso de Pedagogia - UFAL. Maceió - AL - Brasil thayanne.ufal@gmail.com 


\section{Introdução}

A formação de pedagogos foi e vem sendo tema de recorrentes debates no Brasil, especialmente a partir do final da década de I980, quando muitos movimentos de educadores e de suas organizaçóes sociais articularam-se em torno de críticas à formação fragmentada desse profissional e de propostas para a elaboração de novas possibilidades formativas, orientadas por uma perspectiva generalista.

Desse contexto resultaram diversos documentos reorientadores da formação do pedagogo, culminando na instituição das Diretrizes Curriculares Nacionais para o Curso de Graduação em Pedagogia (CNE, 2006), que afirma o referido curso como uma licenciatura voltada para a formação de profissionais aptos a desempenhar atividades de docência

I $\mathrm{Na}$ educação infantil, nos anos iniciais do ensino fundamental e nas disciplinas pedagógicas dos cursos de ensino médio, na modalidade Normal (CNE, 2006, p. 2).

2 "O fato é que há no Brasil, hoje, um novo sujeito social que participa ativamente da luta de classes, com sua identidade e seu nome próprio: Sem-Terra. Neste sentido, Sem-Terra é mais do que sem-terra, exatamente porque é mais do que uma categoria social de trabalhadores que não têm terra; é um nome que revela uma identidade, uma herança trazida e que já pode ser deixada aos seus descendentes, e que tem a ver com uma memória histórica, e uma cultura de luta e de contestação social" (CALDART, 200I, p. 2II, grifo da autora).
- compreendida num sentido amplo -, incluindo o exercício do magistério ${ }^{\mathrm{I}}$ e a participação na organização e gestão de sistemas e instituiçóes de ensino, em experiências educativas escolares e não escolares ( $\mathrm{CNE}$, 2006, p. 2).

A inclusão dos espaços não escolares como locus possível de atuação do pedagogo atende, em certa medida, à reivindicaçáo de entidades de educadores, que assinalavam a necessidade de redefinição do "[...] status epistemológico do campo da educação e da pedagogia [...]”, considerando-se "[...] suas interfaces com a sociedade, a escola e a prática social dos movimentos sociais [...]" (ANFOPE; ANPEd; CEDES, 2004, p. 3).

Neste artigo, objetiva-se apresentar as principais reflexôes resultantes de uma experiência curricular que tomou como objeto a atuação do pedagogo em movimentos sociais - especificamente no Movimento dos Trabalhadores Rurais Sem-Terra² (MST). 


\section{A importância do tratamento das relaçóes entre movimentos sociais e educação na formação de pedagogos}

As relações entre movimentos sociais e educação constituem um vigoroso campo de estudos. O grupo de trabalho Movimentos Sociais e Educação (GT-3), da Associação Nacional de Pós-Graduação e Pesquisa em Educação (ANPEd), é significativo exemplo dessa iniciativa, assim como diversas produções de programas de pós-graduação no Brasil que utilizam, como objeto de análise, o trabalho de educação desenvolvido com o MST. Souza (2007) atesta a expressividade dessas produçóes: entre I987 e 2007, foram mapeados e analisados I50 trabalhos dessa natureza (SOUZA, 2007, p. 444).

Não obstante a afirmação da importância dos movimentos sociais na formação do educador, pouca ênfase vem sendo dada à especificidade da atuação do pedagogo nesses espaços sociopolíticos (CERONI, 2006a, 2006b; PRADO E SILVA; FERNANDES, 2007).

Esse aspecto parece ainda mais problemático quando se considera que, no caso específico do MST, significativas açóes políticas merecem destaque, tais como a influência exercida sobre diferentes níveis de governo na definição de políticas públicas para a educação do campo, o protagonismo na organização e gestão de escolas itinerantes ${ }^{3}$ em diversos acampamentos (MARQUES, 2006), além da atuação direta em escolas públicas localizadas em assentamentos (MARQUES, 2006; BELTRAME, 2002, p. I32-I33).

O trabalho de educação do MST abrange 23 estados brasileiros, alcançando cerca de I.80o escolas públicas de ensino fundamental (MOVIMENTO, 200I, p. 239).
3 As escolas itinerantes tiveram início no Rio Grande do Sul. Baseiam-se, fundamentalmente, no direito de os Sem-Terrinha estudarem em escolas dos seus próprios acampamentos, evitando o risco de interrupçóes na escolarização, em razão de constantes despejos por força judicial. Além disso, essas escolas seguem formas de gestâo e propostas curriculares baseadas na realidade e na perspectiva político-pedagógica do movimento, fazendo uso do preceito legal do direito a formas experimentais de ensino. (MOVIMENTO, 200I). 
Em Alagoas, o MST está presente em mais de 20\% dos 102 municípios, e há assentamentos e acampamentos nas três mesorregiōes do Estado (leste, agreste e sertáo) (SOUZA, 200I, p. 55). É plenamente possível que muitos pedagogos de redes públicas atuem em escolas, nas quais a influência do MST seja uma realidade.

Essas evidências e dados permitem questionar em que medida as propostas de formação de pedagogos levam em consideração as estreitas relaçóes estabelecidas entre o MST e as redes oficiais de ensino. Para tanto, é necessário considerar, na formação desses profissionais, conteúdos referentes à atuaçáo do pedagogo em espaços não escolares. A seguir, será apresentada uma experiência formativa nessa direção.

\section{O percurso metodológico de um estudo sobre a atuaçáo do pedagogo no MST}

A análise da atuação do pedagogo inserido em movimentos sociais, que é tema deste artigo, tem seu início na proposta do componente curricular "Projetos Integradores", previsto na grade curricular do curso de Pedagogia da UFAL. Esse componente objetiva possibilitar aos alunos do curso "[...] a reflexão e a intervenção crítica e criativa no âmbito escolar e não escolar [...]", articulando o "[...] ensino superior de formação do profissional de educação, instituiçấo escolar básica e a comunidade, tendo como eixo a investigação da realidade educativa" (UFAL, 2006, p. 73-74).

Em 2008, a proposta para o desenvolvimento dos Projetos Integradores, apresentada para o $2^{\circ}$ período de Pedagogia pelo conjunto de professores da turma, tratava da atuaçáo do pedagogo em diferentes espaços, tais como empresas públicas, hospitais, terceiro setor, escolas e movimentos sociais.

Uma vez dividida a turma em grupos, as alunas responsáveis pelo espaço dos movimentos sociais elegeram o MST como aquele de maior represen- 
tatividade política e numérica no Estado de Alagoas; além disso, previa-se que esse movimento conferisse grande destaque à educação.

Para o desenvolvimento do estudo exploratório, buscou-se uma abordagem qualitativa, incluindo estudos teóricos, visitas e entrevista, visando conhecer e mapear práticas específicas (DUARTE, 2004) da atuação de um pedagogo no MST.

Os estudos teóricos iniciais sobre o MST (CALDART, 200I; GOHN, 2003, 2005; MORISSAWA, 200I) e sua especificidade em Alagoas (SOUZA, 200I) proporcionaram uma teorização e uma compreensão inicial da realidade a ser observada.

Como atividades de campo, foram realizadas quatro visitas exploratórias (participação num encontro de Sem-Terrinha e idas a acampamentos e assentamentos), conversas informais com militantes do movimento e uma entrevista ${ }^{4}$ com um pedagogo do MST.

Os resultados desse estudo foram socializados em seminário específico, envolvendo todos os alunos e docentes da turma. Dessa forma, os conhecimentos adquiridos pelo grupo estenderam-se ao conjunto de discentes, que não só refletiram sobre seus preconceitos com relação aos movimentos sociais - em especial o MST -, mas também puderam vislumbrar novas possibilidades de atuação do pedagogo e, principalmente, novas propostas educacionais, sob a ótica de populações desfavorecidas e socialmente marginalizadas.

\section{A educação e os movimentos sociais: revelaçóes de um estudo com o MST de Alagoas}

Sabe-se que o ideal do MST não se resume à questáo agrária; portanto, enfatizam-se também outros fatores determinantes para a complexidade da luta empenhada, incluindo a educação.
4 Para a entrevista, foi elaborado e utilizado um questionário semiaberto, com base nas orientaçóes de Chagas (2000) e Duarte (2004). 
A trajetória da luta do MST relaciona-se com a concentração fundiária, que marca o Brasil desde I500 e dá continuidade a diversas formas de resistência popular, tais como os Quilombos, Guerra dos Canudos e as Ligas Camponesas.

O MST consolidou-se como movimento social na década de I980, na sua luta contra a ditadura militar. Em janeiro de I984, ocorreu o primeiro encontro do MST, em Cascavel, no Paraná. A partir daí, começou a se articular um movimento de abrangência nacional, com objetivos e linha política definidos.

Atualmente, o MST está organizado em 24 estados, onde há I30 mil famílias acampadas e 370 mil famílias assentadas. [Em janeiro de 2009], completando 25 anos de existência, o Movimento continua a luta pela Reforma Agrária, organizando os pobres do campo. Também segue a luta pela construção de um projeto popular para o Brasil, baseado na justiça social e na dignidade humana, princípios definidos lá em 1984. (MOVIMENTO, 2009, p. 2).

Em Alagoas, a história e a trajetória do MST acompanham o quadro nacional. O estado ocupa o terceiro lugar no País "[...] em casos de violência cometida contra trabalhadores rurais durante ocupaçóes e despejos" (MOVIMENTO, 2009, p. I). Em 2005, Alagoas foi o estado brasileiro que mais contabilizou prisóes de integrantes do MST; 6 em Maceió e 6 em Arapiraca (MOVIMENTO, 2007). Em 2004, 3029 famílias foram distribuídas em I7 assentamentos (MOVIMENTO, 2006b). Entretanto, em 2005, 4543 famílias permaneciam em acampamentos, dando continuidade à luta pela terra no estado (MOVIMENTO, 2006a).

Pode-se afirmar que a luta do MST perpassa a história do Brasil, de forma que todos os fatos políticos, econômicos e sociais acarretem mudanças na estrutura do MST. Do mesmo modo, muitas ações e políticas públicas são influenciadas pelo Movimento. A política educacional é um caso exemplar: desde a participação direta do MST na definição dos rumos da educaçáo do 
campo até a consideração das demandas de movimentos sociais na formação de educadores, a luta do Movimento se faz presente.

O conhecimento da realidade do MST, em Alagoas, permitiu identificar e compreender sua organização, suas reivindicações e lutas e, principalmente, sua concepção acerca do fenômeno educativo - todos os elementos de uma existência adversa e constantemente ameaçada pela violência.

Tanto nos acampamentos quanto nos assentamentos ${ }^{5}$, foi possível verificar a alta organicidade do movimento, garantida pela subdivisão dos grupos em diferentes setores - coordenação, produção, agricultura, saúde, educação etc. -, estritamente articulados entre si.

Nessa organicidade, a questáo educacional é fundamental para a compreensão da essência do MST: é a partir da educação que o movimento se organiza; não uma educação burocrática, formal, como a tradicional, mas a que ocorre na prática social dos indivíduos. A organização e as decisões coletivas, a troca de conhecimentos entre geraçôes, a definição de papéis sociais em razão das necessidades do movimento, além de outros aspectos, evidenciam que a rotina da luta pela terra é, em si, uma prática educativa. Segundo Caldart (200I, p. 2I2), esse processo materializa "[...] um determinado modo de produção da formação humana, cuja matriz é o próprio movimento como sujeito e princípio educativo" (grifo da autora).

As atividades realizadas no estudo tornaram evidente a dimensão desse princípio desde o primeiro contato estabelecido com um representante do setor de produção na sede do MST, em Maceió.

Outra experiência reveladora do movimento com princípio educativo foi a participação no Encontro Estadual dos Sem-Terrinha ${ }^{6}$, em que centenas de crianças representavam mais de io mil famílias acampadas e assentadas, coordenadas pelo MST em Alagoas. Esse Encontro objetivou entregar ao governador do estado uma pauta de reivindicaçóes das crianças nas áreas da saúde, educação, transporte, esporte e lazer. Durante sua realizaçáo, foram desenvolvidas várias oficinas pedagógicas, fortalecendo as ideias do movimento,
5 O primeiro caso refere-se a uma localidade ocupada, em que os Sem-Terra ainda não alcançaram a posse da terra, fixando-se em moradias improvisadas, geralmente na forma de barracos de lona; o segundo se caracteriza pela legalização da ocupação, em que a posse da terra vem acompanhada da fixação dos trabalhadores rurais - que constroem casas de taipa ou tijolos - e, em alguns casos, instaura-se a produçáo coletiva.

6 Ocorrido entre 8 e $\mathrm{I} 3$ de outubro de 2008 , numa praça localizada no centro de Maceió. 
por meio de atividades lúdicas. No encerramento, ocorreu uma caminhada pelas ruas da cidade de Maceió, com faixas e cartazes - fabricados pelas próprias crianças nas oficinas -, reivindicando suas diferentes demandas.

O diálogo com um grupo de educadores do MST presentes no Encontro evidenciou o envolvimento de muitos militantes com a organização das práticas pedagógicas desenvolvidas com os Sem-Terrinha, ou seja, a educação é tema que envolve a todos do MST, não sendo tarefa exclusiva de profissionais da área que integram seus quadros. Ficou clara a intrínseca ligação da educaçáo com a forma de ser - e mesmo com a continuidade - do MST e a importância de um evento como aquele, tendo a própria luta do movimento como principal conteúdo.

O Encontro revelou a importância da afirmação da identidade dos integrantes do MST desde a infância - é necessário formar o sujeito social Sem-Terrinha, “[...] um nome próprio a ser herdado e honrado” (CALDART, 200I, p. 2I2) -, tendo sido, por si só, um exemplo da questão dessa honra tão prezada pelos militantes.

Após essas experiências, tornou-se latente a necessidade de conhecer

7 "O Incra confirma que a área é um dos focos de conflito agrário no Estado. A área pertencia à Usina Ouricuri [...], que decretou falência na década de 80 . Desde entâo, as terras passaram a ser reivindicadas por movimentos sociais, ex-empregados da usina, posseiros e fazendeiros que afirmam ter comprado parte da propriedade da massa falida" (FOLHA ONLINE, 2005, p. I).

8 A Escola Itinerante foi lançada em Alagoas, em 2006, pela Secretaria Executiva de Educaçấo, atendendo a uma antiga reivindicação dos movimentos de luta pela terra. a realidade do MST em Alagoas. Assim, foram visitados acampamentos e assentamentos localizados no complexo de terras da antiga usina Ouricuri, situada no município de Atalaia7. Vale ressaltar, com base nessas visitas, o difícil acesso à região - que possui uma posição geográfica caracteristicamente montanhosa -, a situação precária dos acampamentos rurais - em contraste com as condiçôes de vida nos assentamentos -, a presença de hortas e plantações, além de uma Escola Itinerante.

A referida escola é um espaço essencial para o andamento do movimento, pois foi iniciada a partir de suas necessidades e lutas para que as práticas e ideologias fossem disseminadas e fortalecidas ${ }^{8}$.

$\mathrm{O}$ conjunto de atividades apresentadas até aqui indica que, quando se tem uma experiência efetiva com o dia a dia do movimento, é fácil constatar quanto seu projeto político-pedagógico-social é grandioso e complexo 
para a realidade das escolas regulares das cidades: ele é "[...] gestado desde o ponto de vista dos camponeses e da trajetória de luta de suas organizaçóes" (CALDART, 200I, apud. VENDRAMINI, 2007, p. I28). Não se trata somente de preparar o sujeito para aceitar e reproduzir um modelo preestabelecido de cidadania, mas também de formar seres pensantes e atuantes, capazes de opinar sobre a sociedade como um todo, em articulaçáo com uma luta social específica.

Considerando esse peculiar e complexo contexto, o que cabe a um pedagogo que atua no MST?

\section{A atuaçáo do pedagogo no MST além do formalismo pedagógico}

O pedagogo é um profissional apto a atuar nas mais diversas áreas, o que lhe exige competências variadas, além de flexibilidade e amplitude de conhecimentos pedagógicos e de vários campos das ciências, que permitam sua inserção profissional em múltiplas áreas que envolvam questôes pedagógicas (CERONI, 2006; PRADO E SILVA; FERNANDES, 2007).

A entrevista realizada com um pedagogo do MST não só comprovou a necessidade da abrangência dessa formaçáo, mas também demonstrou a complexidade dessa tarefa com os movimentos sociais.

O pedagogo entrevistado concluiu o curso Técnico em Contabilidade, em 1984, no nível médio. Licenciou-se em Pedagogia do Campo, pela Universidade Regional do Noroeste do Estado do Rio Grande do Sul (Unijuí)", em 200I. No entanto, sua formação é um processo constante.

Para melhorar sua atuação, o pedagogo entrevistado participa de todas as formações complementares ofertadas pelo MST e afirma que os conhecimentos adquiridos nessas experiências são postos em prática nas atividades que realiza (desde a produção até a ação com os educadores). Ademais, ele
9 Segundo o entrevistado, essa oportunidade surgiu do convênio entre a Unijuí e o movimento. As parcerias com universidades públicas abrem caminhos significativos na trajetória da formação educacional dos Sem-Terra. Souza (2008, p. I09I) salienta que "[...] as experiências do tipo parcerias, entre movimentos sociais, governos e universidades, vêm sendo desenvolvidas no Brasil objetivando a formação de professores. Aproximadamente 28 projetos educativos de nível superior para assentados da reforma agrária estão em desenvolvimento no país, sendo 20 deles cursos de Pedagogia da Terra. Em 2008, sete cursos de licenciatura em educação do campo estavam em fase de aprovação no Ministério de Educação. O curso de Pedagogia da Terra, por exemplo, já existiu em aproximadamente 23 estados brasileiros, tendo surgido na Universidade de Ijuí (RS), em 1998". 
promove trabalhos coletivos e deles participa com outros profissionais como técnicos, geógrafos, assistentes sociais, contadores. Isso revela não só a importância dada pelo movimento à formação de seus militantes, mas também a competência técnica e política do entrevistado e sua capacidade de desenvolver atividades de naturezas diversas. Aqui reside uma importante constatação do que define a atuação de um pedagogo em espaços não escolares; neles, o compromisso político, a consciência da seriedade e importância social do seu espaço de atuação, a capacidade de articular conhecimentos para a solução de problemas reais, o trabalho interdisciplinar, a promoção e coordenação de diferentes atividades, entre outros, são aspectos da prática transcendentes à sala de aula e à dinâmica de uma escola tradicional - que exigem uma atuação inventiva, que só se justifica se for importante para a prática social em questão. No caso do MST, a atuação do pedagogo é direcionada por uma concepção de educação que “[...] comporta vários aspectos teóricos e ideológicos, bem como diversas práticas educacionais” (DAL RI; VIEITEZ, 2004, p. 45).

O MST trabalha em regime de colaboração no desenvolvimento de suas atividades. Por esse motivo, o pedagogo entrevistado - que atua há 23 anos no MST - e todos os outros sujeitos Sem-Terra desempenham açóes nos mais diferentes setores, tendo o entrevistado atuado em diversos âmbitos do movimento. No início, exerceu a função de pedagogo, assumindo a coordenação regional do setor de Educação; ministrou aulas de matemática no Instituto de Educação Josué Castro, no Rio Grande do Sul; integrou a co-

Io Instituto Técnico de Capacitação e Pesquisa da Reforma Agrária, localizado em Veranópolis, Rio Grande do Sul. Desenvolve programas na área de saúde, administraçáo de cooperativas e magistério, sendo coordenado pelo MST. ordenação do ITERRA ${ }^{\text {Io }} \mathrm{e}$ atualmente, em Alagoas, desenvolve trabalhos no setor de produção, além de promover atividades de formação de professores. Esta última forma de atuação é justificada, principalmente, pela distância entre as propostas pedagógicas das escolas públicas e os objetivos educacionais do MST. Em geral, as escolas rurais carecem de políticas de formação docente, ocasionando problemas de diversas ordens, tais como "[...] falta de propostas de formação contínua por parte dos órgãos gerenciadores dos siste- 
mas de ensino; inadequação da formação supletiva para professores das zonas rurais" (BELTRAME, 2002, p. I37).

Isso demonstra a fragilidade, ainda tão visível, das escolas do campo. Segundo o entrevistado, por falta de recursos governamentais e políticas efetivas de formação, essas escolas geralmente atuam por meio de improviso e colaboração da comunidade campesina. Por isso, os cursos formativos organizados pelos pedagogos do movimento são de extrema importância, pois capacitam os educadores não só para os conteúdos curriculares ${ }^{\mathrm{II}}$, mas também para o fortalecimento das posiçôes político-ideológicas do MST.

Os depoimentos do pedagogo permitiram compreender como a educação assume um lugar central no movimento, conforme vários estudos afirmam (CALDART, 200I; GOHN, 2003, 2005; MORIGI, 2003). Dessa forma, o pedagogo, antes de ser um profissional da educação, é um "educador/militante", visto que os Sem-Terra se educam, "[...] se humanizam e se formam como sujeitos sociais no próprio movimento da luta que diretamente desencadeiam" (CALDART, 200I, p. 2I2). Acerca disso, Morigi (2003, p. 90) reflete:

A proposta para educação do MST está afinada com os interesses, as concepçóes de trabalho e as relaçóes sociais dos trabalhadores Sem-Terra e, talvez por isso, cause preocupação às classes hegemônicas, que conhecem o poder da educação como ferramenta capaz de instrumentalizar o povo para a conquista das condiçôes de compreensão de sua situação, se organizar e lutar pelo seu desenvolvimento e pelos seus interesses sempre negados.

O autor expressa exatamente a intencionalidade da educação do MST, que objetiva não apenas a socialização de saberes técnicos, mas também a formação de senso crítico dos Sem-Terra, para estimular e orientar posiçóes e açôes políticas condizentes com os objetivos do movimento. Portanto, no que se refere ao processo educativo, o pedagogo exerce funçóes que condizem com
II No caso estudado, os cursos de formação eram dirigidos a educadores do próprio movimento; entretanto, em algumas regiōes do País, diferentes práticas são desenvolvidas com professores de redes públicas que atuam em suas localidades. "A proposta do MST de investir no processo de formaçáo de sujeitos, dentro do espaço oficial de ensino, ou seja, da escola pública, é um desafio, uma vez que não são frequentes experiências desse tipo" (BELTRAME, 2002, p. I32). 
aquela finalidade educativa; por isso, não é possível segregar suas funçóes, pois elas são partes constitutivas e constituintes do MST. Em consequência, as condiçóes possíveis para que um pedagogo atue no movimento, segundo o entrevistado, é sua pertença ao MST e/ou a participação em projetos conveniados com outras instituiçóes; de toda a forma, é preciso que esteja comprometido com o trabalho militante.

Com relação a sua atuação como pedagogo no movimento, o entrevistado afirmou que as dificuldades estão na falta de incentivos e de políticas públicas voltados para atender às necessidades dos militantes. A própria sustentabilidade financeira do MST foi um tema apresentado, uma vez que a luta é subsidiada pelas famílias engajadas e pelos programas governamentais, e as demandas e necessidades são muito superiores aos recursos disponíveis. No MST, essa é uma questão que deve envolver a todos, incluindo os pedagogos que atuam em suas atividades.

Quanto aos objetivos pessoais nas diferentes formas de atuação como "pedagogo militante", o entrevistado arrolou os seguintes: ver o povo escolarizado; ajudar no desenvolvimento dos assentados; promover uma inserção social das pessoas envolvidas em movimentos sociais, e formar novos coordenadores capazes de dar continuidade ao seu trabalho. Esse depoimento confirma o fato de que,

[...] Para o Movimento, não basta que o militante tenha formação política, ainda que esta seja essencial. Paralelamente a essa qualidade, o Movimento precisa que o seu membro tenha também capacitação técnica, bem como desenvolva as aptidōes necessárias à organização coletiva da vida social, à organização coletiva da produção e de outras atividades econômicas. Esses requisitos derivam de uma característica organizacional insólita do MST no contexto das organizaçôes populares, ou seja, o fato de que três instâncias da realidade social - a política, a econômica e a social -, que se encon- 
tram normalmente separadas nas práxis de outras organizações, no MST encontram-se organicamente reunidas (DAL RI, VIEITEZ, 2004, p. 46).

Em suma, a atuação de pedagogos em movimentos sociais é um desafio técnico-político que pressupóe o rompimento com o formalismo pedagógico, marcado pela incoerência entre o discurso e a prática e pelo contraste entre práticas e princípios (PAIVA, 2000, p. 47); enfim, pela ausência de uma práxis efetiva. Apesar do desafio, o entrevistado concluiu seu depoimento com um recado aos futuros pedagogos: "Diria que é difícil, mas vale a pena”.

\section{Consideraçóes finais}

Quem visita um assentamento, ou mesmo um acampamento de Sem Terra, sai com a impressão, e talvez a reflexão, de que há outras possibilidades de como viver, e que há questôes, saberes, afetos e relaçôes de outra ordem, acontecendo não muito longe de um tipo de vida que consideravam como único possível (CALDART, 200I, p. 216).

O conhecimento dos fundamentos e da realidade do MST tem o efeito da citação acima: provoca a necessidade de ampliação de perspectivas teóricas, práticas, políticas e pedagógicas - históricas, enfim.

Quanto à atuação do pedagogo, o contato com a realidade do MST exigiu o questionamento das diferentes concepçôes de educação e a reflexão de como se relacionam com a vida social dos indivíduos. Isso permitiu repensar, questionar e discutir preconceitos, muitas vezes reforçados pela ignorância do sentido da luta empenhada pelo movimento e de sua forma de constituir-se como tal. 
Tendo em vista que a pedagogia abrange o campo técnico-investigativo da educação, do ensino, de aprendizagens e do trabalho pedagógico que se realiza na práxis social, as atividades do profissional da área envolvem a docência, a gestão de processos educativos em ambientes escolares e não escolares, e ainda a produção e disseminação de conhecimentos da área da educação. Essa perspectiva generalista ganha um significado ainda maior quando encarnada em realidades múltiplas, díspares, complexas e historicamente concretas, como é o caso dos movimentos sociais. Conhecê-los exige dos pedagogos a compreensão de que tais movimentos são expressão das contradiçóes próprias do sistema capitalista - que geram uma sociedade essencialmente conflituosa - e que é impossível colocar-se de forma neutra perante elas, especialmente em se tratando da educação.

Os paradigmas conservadores presentes na sociedade são barreiras difíceis de quebrar; por isso, uma boa maneira de tentar provocar uma mudança de visão de mundo e de ampliar as possibilidades de ação é o conhecimento de realidades contestadoras, que explicitam e encarnam conflitos e contradiçóes.

Ao final deste artigo, fica o convite para que todos os pedagogos, licenciados e em formação, busquem conhecer a realidade dos movimentos sociais, sua dinâmica, suas lutas e reivindicaçôes. Fica também a sugestão de que os cursos de pedagogia "frequentem", de alguma forma, uma escola chamada Movimento dos Trabalhadores Rurais Sem-Terra.

\section{THE ROLE OF THE TEACHER IN THE MST: REVELATIONS OF AN EXPLORATORY STUDY}

In 2006, the graduate programs in Pedagogy were defined as a degree that should provide the training of performance of the professional in schools and other spaces, including social movements. This paper aims to present a curricular experience called "integrated projects", which took as its object the performance of the teacher in Brazilian landless 
workers' movement (MST), and involved teachers and students of the second period of the course of Pedagogy at the Universidade Federal de Alagoas (UFAL). The article reflects on the importance of treatment of the relationship between social movements in education and training of teachers. It is presented a methodological course of the study, and it is also exposed a significant learning that it offers, with emphasis on understanding the relationship between the struggle for land and education, considering the actions taken by a teacher in the MST.

KEY wORDs: Education and MST. Education and social movements. Role of the pedagogue.

\section{Referências}

ANFOPE. ANPEd. CEDES. A definição das diretrizes para o curso de Pedagogia, set. 2004. Disponível em: http://www.anped.org.br/200904PosicaoDiretrizesCursosPedagogia.doc.

Acesso em: 23 ago. 2008.

BELTRAME, S. Formação de professores na prática política do MST: a construção da consciência orgulhosa. Educação e Pesquisa, São Paulo, v. 28, n. 2, p. I29-I45, jul./dez. 2002. Disponível em http://www.scielo.br/pdf/ep/v28n2/aIov28n2.pdf. Acesso em: I2 ago. 2008.

CALDART, R. O MST e a formação dos sem terra: o movimento social como princípio educativo. Estudos Avançados, São Paulo, v. 15, n. 43, p. 207-224, set./dez. 200I. Disponível em: http://www.scielo.br/scielo.php?script=sci_arttext\&pid=SoI03-40I4200I0003000I6.

Acesso em: 22 ago. 2008.

CERONI, M. R. Ética e Trabalho: os valores dos pedagogos que atuam em espaços não escolares. In: II Congresso Internacional de Ética e Cidadania. Revista Eletrônica de Comunicaçōes, São Paulo, v. I, p. I9-30, 2006a. Disponível em: http://www4.mackenzie.br/ fileadmin/Graduacao/EST/Revistas_EST/II_Congresso/cadernos/caderno_de_trabalho. pdf. Acesso em: 2 jul. 2008.

. O perfil do pedagogo para atuação em espaços não escolares. In: Anais do I Congresso Internacional de Pedagogia Social, 2006b, Universidade de São Paulo, p. I-I6. Disponível em: http://www.proceedings.scielo.br/scielo.php?script=sci_arttext\&pid=MSCo $000000092006000100040 \& \operatorname{lng}=$ en\&nrm=abn. Acesso em: 2 jul. 2008. 
CHAGAS, A. T. R. O questionário na pesquisa científica. Administração online, São Paulo, v. I, n. I, p. I-I 4, 200o. Disponível em: http://www.fecap.br/adm_online/arti I/anival.htm. Acesso em: I4 jul. 2008.

CONSELHO NACIONAL DE EDUCAÇÃO. Resolução CNE/CP $n^{\circ} 1$, de Is de maio de 2006. Institui Diretrizes Curriculares Nacionais para o Curso de Graduação em Pedagogia, licenciatura. Disponível em: http://portal.mec.gov.br/cne/arquivos/pdf/rcpor_o6.pdf. Acesso em: 25 mai. 2008.

DAL RI, N.; VIEITEZ, C. A educação do movimento dos sem-terra. Revista Brasileira de Educação, Campinas, n. 26, p. 44-57, maio/jun./jul./ago. 2004.

DUARTE, R. Pesquisa qualitativa: reflexóes sobre o trabalho de campo. Cadernos de Pesquisa, São Paulo, n. I I5, p. I39-I54, mar. 2002. Disponível em: http://www.scielo.br/ scielo.php?script=sci_arttext\&pid=SoI00-I $5742002000100005 \& \operatorname{lng}=$ pt\&nrm=iso. Acesso em: 7 jul. 2008.

FOLHA ONLINE. Lider do MST é assassinado em Alagoas. 29 nov. 2005. Disponível em: http://wwwi.folha.uol.com.br/folha/brasil/ult96u7426I.shtml. Acesso em: 7 fev. 2009.

GOHN, M. G. M. Movimentos sociais e educação. 6 ed., São Paulo: Cortez, 2005.

Movimentos sociais no início do século XXI: antigos e novos atores sociais.

Petrópolis: Vozes, 2003.

MARQUES, M. Relação Estado e MST: algumas fases e faces. Lutas \& Resistências, Londrina, v.I, p. I84-I96, set. 2006. Disponível em: http:<//www2.uel.br/grupo-pesquisa/ gepal/lri84-ig6.pdf. Acesso em: 23 fev. 2009.

MORIGI, V. A escola do MST: uma utopia em construção. Porto Alegre: Mediação, 2003.

MORISSAWA, M. A história da luta pela terra e o MST. São Paulo: Expressão Popular, 200 .

MOVIMENTO DOS TRABALHADORES RURAIS SEM-TERRA. 25 anos de lutas e conquistas. Jornal dos Trabalhadores Rurais Sem-Terra, 298 ed., 30 jan. 2009. Disponível em: http://www.mst.org.br/mst/jornal_pagina.php?ed=82\&cd=6249. Acesso em: 30 mar. 2009.

Acampamentos 2005. Biblioteca - Dados, I4 jul. 2006a. Disponível em: http:// www.mst.org.br/mst/pagina.php?cd=87I. Acesso em: 30 mar. 2009.

. Assentamentos do MST em 2004. Biblioteca - Dados, I4 jul. 2006b. Disponível em: http://www.mst.org.br/mst/pagina.php?cd=IoIo. Acesso em: 30 mar. 2009. 
. Escola Itinerante em acampamentos do MST. Estudos Avançados, Sáo Paulo, v. I5, n. 42, p. 235-240, maio/ago. 200I. Disponível em: http://www.scielo.br/pdf/ea/visn42/ visn42aiI.pdf. Acesso em: I2 ago. 2008.

. Prisóes 2005. Biblioteca - Dados, in jul. 2007. Disponível em: http://www.mst. org.br/mst/pagina.php?cd=1503. Acesso em: 30 mar. 2009.

PAIVA, J. M. Educação jesuítica no Brasil colonial. In : LOPES, E. et. al. 500 anos de educação no Brasil. Belo Horizonte: Autêntica, 2000.

PRADO E SILVA, L; FERNANDES, T. O pedagogo em espaços não escolares. In: Anais do Encontro Americano de Iniciação Científica, 11 e Encontro LatinoAmericano de Pós-

Graduação, 7. Universidade do Vale do Paraíba, p. 3018-3021, 2007. Disponível em: http:// www.inicepg.univap.br/INIC_o7/trabalhos/humanas/inic/INICGoo75I_oIC.pdf. Acesso em: 25 jul. 2008.

SOUZA, D. R. Reforma agrária: as experiências em Alagoas (1980-2000). Maceió: EDUFAL, 200I.

- A pesquisa sobre educação e o Movimento dos Trabalhadores Rurais Sem- Terra (MST) nos Programas de Pós-Graduação em Educação. Revista Brasileira de Educação, Rio de Janeiro, v. I2, n. 36, p. 443-548, set./dez. 2007.

Educação do campo: políticas, práticas pedagógicas e produção científica.

Educaçấo e Sociedade, Campinas, v. 29, n. I05, p. I089-I I I I, set./dez. 2008. Disponível em http://www.scielo.br/pdf/es/v29nio5/v29niosa08.pdf. Acesso em: 28 mar. 2009.

UNIVERSIDADE FEDERAL DE ALAGOAS. Projeto Político-Pedagógico do Curso de Pedagogia. UFAL, 2006.

VENDRAMINI, C. Educação e trabalho: reflexôes em torno dos movimentos sociais do campo. Caderno Cedes, Campinas, v. 27, n.72, p. I2I-I35, maio/ago. 2007. Disponível em: http://www.scielo.br/pdf/ccedes/v27n72/a02v2772.pdf. Acesso em: 7 abr. 2009.

Recebido em I5 abr. 2009 / aprovado em I5 maio 2009.

\section{Para referenciar este texto}

CÊA, G. S. dos S. et al. A atuação do pedagogo no MST: revelaçôes de um estudo exploratório. EccoS, São Paulo, v. II, n. I, p. I75-I9I, jan./jun. 2009. 
